\title{
No-alineación y política mundial
}

\section{contemporánea}

JOHX WEAR BCRTON ocupa el cargo de Reader in International Relations en el Lniversity College London. Ha publicado los siguientes libros: International Relations: A General Theory. (Cambridge University Press, 1965). Monalignmenl (cditor and contributor). (Andre Deutsch, 1966). Systems, States, Diplomacy and Rules. (Cambridge University Press, 1968). Conflict and Communication. (MacMillan, June 1969).

Diez años atrás se hablaba y se escribia más sobre la no-alineación*. Los lideres de los estados no-alineados hoy parecen menos inclinados que antes a hacer públicas actitudes comunes y a presentarse como tales. Bandung en 1955 y Belgrado en 1961 fueron ocasiones en las que los estados no-alineados se reunieron para plantear su lugar en los asuntos contemporáneos. Separada o colectivamente estuvieron hablando - según las palabras de Abdul Gamal Nasser- de "un paso verdadero hacia la paz, justa, sin restricciones, convencidos de que la justicia debe ser su fundamento" (último párrafo del discurso de apertura en Belgrado). Desde entonces no ha habido otras reuniones $y$ han sido muy pocas las declaraciones sobre su papel especifico. ¿Fue la no-alineación sólo una moda pasajera, una fase temporal en el desarrollo de los estados nuevos y recientemente independizados, una común reacción contra las intensas rivalidades entre las potencias nuclerares en la Guerra Fria, una explosión de idealismo en lideres que tendrian aun que sufrir la experiencia en el mundo de la politica? $O$ al contrario, en su calidad de alianzas, $\dot{i}$ se trata de algo de tal modo aceptado en la politica internacional y en la orientación nacional, que debemos tomarla como un hecho? Si es lo segundo, ¿está clara su naturaleza y su significación? Después de dos décadas estamos en un oportuno momento para mirar atrás y volver a evaluar, tanto las pretensiones como la naturaleza de la no-alineación, el grado de su realidad y sus posibilidades de seguir adelante.

Desde el exterior, el término en si mismo pareció insatisfactorio. Se tuvo especial cuidado en dejar en claro que no se trataba de neutralidad o de marginación respecto de los asuntos mundiales. Se insistió, al contrario, en que la no-alineación tenia un aspecto positivo: los estados nuevos, los pequeños $y$ los grandes, tenian el derecho $y$ el deber de interesarse $y$ de

\footnotetext{
"Hemos traducido "nonalignment" por no-alineación. La complejidad del concepto hace que esta traducción no sea del tedo sitislactoria.
} 
J. W. Burton / No-alineación y politica mundial contemporánea

plantear sus juicios sobre todos los aspectos que interesaran en lo internacional. No se trataba simplemente de implementar una reacción contra la existencia de los dos grandes y poderosos bloques militares. Las naciones de Bandung y de Belgrado no formaron una tercera fuerza. Algunos lideres avanzaron declaraciones en sentido de que permanecerian no-alineados respecto a cualquiera tercera fuerza que pudiera emerger. El énfasis fue puesto en la libertad que tienen los estados para establecer sus propias decisiones politicas respecto a cualquier materia que enfrentaran. En este sentido, no-alineación cobró una connotación de antinterferencia, y por ello mismo de anticolonialismo y de antigrandes potencias.

Para los otros estados, y en particular para las grandes potencias, la noalineación vino a ser un inoportuno voto de desconfianza en el manejo de los asuntos mundiales, en el preciso momento en que cada lado del conflicto ideológico estaba evaluando los beneficios universales que se derivarian de su liderazgo. La Unión Soviética y China, no menos que Estados Unidos, adoptaron la perspectiva de que "cualquier estado que no esté con nosotros está contra nosotros". Ser no-alineado era no dar un apoyo activo hacia un lado o hacia el otro, era rechazar a ponerse de pie para ser tomado en cuenta, y era, según como veia las cosas el señor Dulles, algo inmoral. En los recientes años cincuenta, las grandes potencias, en especial la Unión Soviética y China, pero también el Occidente, como sucedió en el caso de Laos, pudieron ver alguna ventaja en la no-alineación, cuando la alternativa podia ser el irse al campo contrario. Se toleró la no-alineación en base a que "cualquier estado que no está contra, podrá estar con nosotros en circunstancias diferentes o en algunos problemas determinados".

El término desafortunadamente inadecuado, el fracaso de los lideres en su intento por traducir el concepto de no-alineación en posiciones politicas o en una filosofia claramente expresadas, y las cinicas interpretaciones que hicieron las grandes potencias de aquellos aspectos que venian a afectar sus propias planificaciones estratégicas, se concertaron para dejar la impresión de que la no-alineación fue y es poco menos que un expediente inventado, mediante el cual los donantes de ayuda y de defensa son manipulados unos contra otros, que da a los lideres de los estados pequeños la oportunidad de manifestar sus desacuerdos, como independientes gestores de decisiones, a través de extravagantes declaraciones de independencia.

No es sorprendente que en estas circunstancias se fraguara confidencialmente el fin de la no-alineación, al ser atacadas las Repúblicas Arabes Unidas por Francia y Gran Bretaña en 1956, y cuando en 1962 la India sintió amenazada su seguridad, con ocasión de un conflicto limitrofe con China. Hubo un cierto alivio en Occidente cuando estos sucesos parecieron confirmar los conceptos sobre la naturaleza de la no-alineación. Se veia ahora más claro que se trataba de una actitud que, como la neutralidad, sólo 
E S T U D I O S I N T E R N A C I O N A L E S

era posible con la ayuda del poder armado de las grandes potencias y su disuasión contra el ataque a los pequeños estados. Los acontecimientos parecian confirmar que la no-alineación no era capaz de sustentarse a si misma. Se veía posible para los estados pequeños solamente en el caso de ausencia de conflictos que requirieran el apoyo de alianzas foráneas. No era sino un lujo de tiempos de paz. O una conveniencia que no viniera a alterar las relaciones de poder entre los grandes estados, o las bases de poder de la politica mundial. Sin embargo, las Repúblicas Arabes Unidas y la India continuaron declarándose no-alineados.

La no-alineación como cualquier otra orientación politica, puede ser considerada viable en cuanto a su naturaleza y su permanencia, solamente dentro de la trama de las fuerzas que están determinando la naturaleza y las operaciones de la sociedad mundial. Su utilidad puede determinarse sólo en base a los valores que persiguen los estados que la adoptan. El diálogo no deberia fundarse en las tradicionales concepciones occidentales acerca de la sociedad mundial, dentro de las que tantas veces ha sido analizada y discutida la no-alineación; ni en los valores de las grandes potencias y en la trama de poder en que ellas operan, o en las metas de defensa de las estructuras e instituciones internacionales hoy por hoy existentes. Es claro que la no-alineación tiene su status y una importancia muy limitada en un mundo gobernado por potencias politicas, o en un mundo en el que la seguridad es el principal valor. Vendria a ser la politica obvia de los estados, sólo en un mundo en que las comunicaciones lograran que la gente se preocupase de sus oportunidades y de sus derechos, con posibilidad de alcanzarlos; en el que esos nuevos estados que se han creado de anteriores imperios estuvieran buscando su independencia, en el que hubiera un consenso que negara a los grandes estados cualquier derecho de intervención en los asuntos ajenos; en el que el lógico avance en el uso de las armas nucleares hubiera terminado con las hegemonias de poder, y en el que los derechos humanos y nacionales a tomar parte en las decisiones, fueran elevados al rango de los valores más importantes que la seguridad y que las instituciones politicas y sociales existentes. La pregunta de si la noalineación fue una moda pasajera o una politica de simple expediente, o si se trata de un fenómeno permanente, queda supeditada a la respuesta sobre una pregunta más fundamental: ¿cuáles son las fuerzas que hoy influyen y que probablemente en el futuro influirán la naturaleza de la sociedad mundial contemporánea, y cuáles son los valores que se buscan y que se buscarán?

Se argumentará en este trabajo que en una perspectiva retrospectiva la no-alineación parece haber sido un intento de búsqueda de una concepción nueva en la sociedad mundial, un modelo o una explicación de las relaciones entre los pueblos y entre los estados. Que es más realista y concordante con las circunstancias contemporáneas y con los caminos futuros, que los modelos 


\section{J. W. Burton / No-alineación y politica mundial contemporánea}

o explicaciones empleados por las grandes potencias para dar cuenta de sus conductas politicas. Por este motivo, la no-alineación deberá ser considerada como un rasgo importante y permanente de la politica mundial. Sin embargo, se mostrará también cómo los lideres politicos de los estados que fueron no-alineados, bajo presiones domésticas tienden a adoptar las actitudes $y$ las conductas politicas de las grandes potencias; cómo están promoviendo centros de poder, y están destruyendo la no-alineación no menos que los mismos antiguos colonialistas o imperialistas de hoy que ellos criticaron. Son en realidad los estados medianos y los ya desarrollados los que, hoy por hoy, más se inclinan a llevar la bandera de la no-alineación en el futuro.

\section{DIFERENTES PERCEPCIONES DE LA SOCIEDAD MUNDIAL}

La tragedia fue que cuando el señor Nehru y otros, por primera vez propusieron la no-alineación, pareció que describían solamente una orientación politica alterada, una conducta politica astuta, un conjunto de actitudes que parecian diferentes a las de los estados alineados, pero que de hecho estaban adentro de la misma armazón. La no-alineación que proponian, implicaba una conducta apropiada para ciertos estados más pequeños, en un mundo en que ya habia poderosas alianzas. Lo que ahora es claro al dar una mirada retrospectiva, es que la no-alineación implicaba no tanto una modificación en la conducta de los estados pequeños, sino toda una perspectiva diferente sobre la sociedad mundial, y un cambio de conducta para todos los estados que dentro de ella estaban. No pudieron reprocharle esto al señor Nehru. Al contrario, comenzaba él a percibir algo que sólo en los últimos años se ha hecho patente. En el frente politico, De Gaulle ha tomado conciencia y ha llamado la atención al mundo sobre lo mismo. Hoffman ha analizado las diferentes percepciones que de la sociedad mundial tienen Francia y Estados Unidos de América. Al hacerlo, ha arrojado luz sobre la naturaleza de la no-alineación. "Desde 1947 ha dominado la imagen norteamericana de los asuntos internacionales, y el papel de América en ellos. La politica mundial fue mirada como una disputa que colocaba a las fuerzas de orden, de estabilidad y de cambio evolutivo frente a las fuerzas de la agresión y de la subversión. El papel de las primeras era contener a las últimas, de un modo tal que los hombres de estado con malas intenciones no solamente vieran contrariadas sus empresas, sino llegaran a la conclusión de que por su propio interés les era conveniente cambiar sus formas de pensar, y jugaran asi un papel responsable, es decir, no violento, dentro de la sinfonía global. El papel de las fuerzas de orden consistia también en alentar en cualquier lugar, a los lideres politicos y a los grupos que se presentaran en favor de la moderación. Los que conforman la politica americana miraron a Estados Unidos como la única nación que, 
tanto por necesidad como por vocación, llevaba el peso de responsabilidad mundial en esta batalla por el orden. Solamente Estados Unidos tenia la combinación de poder, valores, instituciones e intereses necesarios para el liderazgo sobre todo el globo".

"Tres elementos de esta imagen cobran especial valor en la crisis francoamericana. Primero. la perspectiva americana sobre los asuntos internacionales reúne tanto la noción de un duelo entre dos grupos - podria hablarse de una disputa entre blanco y negro- cuanto la idea de una postrera, aunque dificilmente conseguida, armonia. Segundo, una perspectiva como ésta provee a Estados Unidos de un criterio aparentemente simple para evaluar la conducta de las otras naciones: estarán dentro o fuera de su favor según si su desempeño obstaculice o contribuya en el esfuerzo por construir una efectiva barrera común contra las fuerzas de la armonia. Tercero, se encuentra en el enfoque americano lo que podria llamarse una actitud de superioridad desinteresada: superioridad, debido a una profunda convicción de que el sentido americano de esfuerzo y de responsabilidad provee a la politica exterior de Estados Unidos de una cinta para medir lo que es mejor en el interés de los demás; desinteresada, porque esta cinta para medir es usada dentro de una concepción de lo común, más que para el mero bienestar americano".

"La perspectiva francesa sobre los asuntos internacionales choca a cada paso con la americana. Los lideres franceses - y especialmente De Gaulle-ven la politica mundial como una disputa múltiple, en la que el esfuerzo por dividir a los contendores en dos campos es peligroso e inútil: peligroso, porque una tal división amenaza tanto la paz como la independencia de los actores más débiles; inútil, porque en la esencia del contexto internacional está el que los campos ideológicos y las alianzas militares se desintegren bajo las presiones de los intereses nacionales. Resultado: cualquier expectativa de una armonía final aparece ingenua. Al contrario, el rango de las opciones se mueve en una gama de grises, que va desde la belicosa inestabilidad hasta la frágil moderación. En un mundo como éste, los franceses esperan que el o los pobres dominantes busquen preservar y mantener su poderio, racionalizarlo o disfrazarlo — sea por autoengaño o sea para engañar a otros- bajo un manto de mesianismo ideológico o de altruismo universalista. En cuanto a los poderes menores, aunque la única opción que les queda sea buscar la protección de un gigante, su interés y por ello su deber está en mantener un margen de autonomia, para mantener su propia integridad y el respeto a si mismos, y para no dejar de lado la posibilidad de restaurar un sistema de orden mundial que viniera a moderar los choques y a contrapesar las pretensiones de los grandes".

"Es también importante el impacto de posición en el tablero de la politica mundial de ambas naciones. Estados Unnidos considera los asuntos internacionales y la conducta politica de Francia desde el punto de vista de una 


\section{J. W. Burton / No-alineación y politica mundial contemporánea}

superpotencia que da una batalla esencialmente defensiva en un sistema internacional revolucionario. Casi por necesidad, tal nación tiende a apreciar las jugadas de los otros bajo la luz de una estrategia en la que ella sola tiene la responsabilidad y los medios para definirla y aplicarla. Consecuentemente, Estados Unidos reacciona con menos impaciencia e irritación frente a desacuerdos limitados dentro de su campo y frente a desafios locales de sus inquietos asociados, que frente a un desafio tan amplio y fundamental como el de De Gaulle. Los pequeños desacuerdos afectan sólo la ejecución de una estrategia cuyos grandes rasgos no son tocados; son disturbios menores dentro de un sistema internamente controlado. La politica de De Gaulle parece, al contrario, cuestionar la legitimidad misma de los postulados americanos, de sus pretensiones y de su forma de emplear el poder".

"Finalmente, los procedimientos que siguen ambas naciones en su politica exterior dan cuenta en una buena parte de las diferencias en sus enfoques Las técnicas en los procesos de decisión americanos, que combinan la inclinación nacional hacia un pragmatismo ad hoc con un formidablemente complejo proceso de regateo y de burocrática formación de consenso, da a menudo como resultado decisiones de corto alcance. Las de largo alcance surgen más en forma de principios generales con alcance moral, que como un conjunto de conexiones políticas y de relaciones de poder posibles y deseables. Tanto la magnitud de las tareas emprendidas por los gestores de las decisiones en la politica exterior americana, asi como la naturaleza de su maquinaria, tienden a producir crisis en la diplomacia, dejando a mano decisiones disponibles en o para casos de emergencia, sin tocarlas (dejando que sus efectos sigan su curso) hasta la próxima emergencia " (Stanley Hoffman, "Perceptions, Reality and the Franco-American Conflict", en Image and Reality in World Politics, J. C. Farrel y A. P. Smith, editores, Columbia University Press, 1967).

A nivel académico, los que han analizado la sociedad mundial en términos de sistemas y de comunicaciones que sobrepasan los limites de los estados han dado contenido a esta nueva perspectiva. (Ver los trabajos de D. Easton, K. Deutch y mi reciente estudio Systems, States, Diplomacy and Rules, Cambridge, 1968). Para dar cuenta de influencias otras que el poder, tales como la transmisión de valores, expectativas y posibilidades en sus enfoques y América Latina, se necesita un modelo de la sociedad mundial radicalmente diferente de los modelos tradicionales. El origen de las expectativas se ubica en gran medida en Ia Segunda Guerra Mundial, y como consecuencia de la invasión japonesa en el Sudeste Asiático, que dio oportunidad al florecimiento de movimientos nacionalistas. Los medios de transmisión siguieron a los avances que habian aportado las comunicaciones y las posibilidades de comercio, ampliando en la gente la conciencia sobre las posibilidades de independencia, de una justa distribución del fruto de su 
trabajo, y de la participación en las decisiones que los afectaban. Relacionado con esto, los avances tecnológicos condujeron también a una mayor interdependencia internacional, especialmente en cuanto a la organización internacional de la industria. Es más realista tener ahora en mente, no un modelo del mundo en el que hay una cantidad de entidades estatales, poderosas unas débiles las otras, sino un modelo que ponga el acento en las transacciones, lazos, sistemas y comunicaciones. Un modelo de sociedad mundial que dibuje un racimo de entramados, que represente transacciones centradas en varios puntos geográficos, cuyos limites puedan o no coincidir con los limites politicos. Un modelo tal es más realista que los tradicionales, con entidades estatales separadas, unidas por relaciones de poder.

Este modelo de la sociedad mundial contemporánea hace más patente el papel de los gobiernos de los estados, y en particular el papel de los gobiernos de esos Welfare States que los paises no-alineados tratan de alcanzar. Uno de los papeles del estado es la protección del área geográfica, delimitada por limites fijos, respecto a la incontrolada influencia de las transacciones que tienden a cruzar esos limites. Puede conseguir esto mediante la ayuda interna, la protección del limite y la actividad más allá del limite. La medida en que las autoridades hacen esto determina el grado en que aislan los sistemas de la comunidad respecto a los sistemas internacionales. Cuando los limites de la autoridad son idénticos a los limites de los sistemas el aislamiento es perfecto. Esta fue una situación general antes del desarrollo del sistema internacional, pero en el mundo contemporáneo el aislamiento es virtualmente imposible. Se está viendo la imposibilidad de aislar a las comunidades aun de las ideas. Pero si es posible un cierto grado de aislamiento en asuntos de corto alcance, $y$ es a los asuntos de corto alcance a los que se dedican las autoridades. En último término, las tensiones internas y los conflictos entre miembros de comunidades que no desean ser protegidos de la influencia de sistemas foráneos, las tensiones entre los estados y los conflictos que surgen de transacciones interrumpidas, tienden a reducir el poder de las autoridades y a destruir las politicas aislacionistas.

Se plantea la cuestión de si es posible aislar un estado de la politica mundial, esto es, eliminar la intervención de otros estados en sus procesos políticos, cuando los sistemas que están entramados dentro del estado se extienden más allá de sus limites y tienen significativos subsistemas centrados en otros estados. Es ésta la posición de Estados Unidos de América. ¿Será posible para Estados Unidos elụdir sus compromisos politicos y estratégicos en otros paises, mientras sus sistemas comerciales, culturales e ideológicos se extienden hasta ellos?

Aisląmiento no es lo mismo que neutralidad. En una guerra, un estado neutral tiende a eliminar la influencia de la guerra cuidándose de no actuar en favor de alguno de los beligerantes. Esto puede o no implicar transaccio- 


\section{J. W. Burton / No-alineación y politica mundial contemporánea}

nes de menor monto. La no-alineación es un sistema para ampliar y no para reducir las transacciones. Es una situación en la cual hay interacciones e interdependencia a nivel de sistemas: cada estado afirma el derecho de determinar sus propios valores, pero no el de imponer sus valores a los demás. Las firmas comerciales extranjeras estarian obligadas, en estas condiciones, a negociar con las autoridades de los estados dentro de los que están operando sin ningún soporte de sus propios gobiernos. En cuanto politica exterior, la no-alineación busca permitir a la comunidad el abrirse a la influencia de todos los sistemas extranjeros. Cumpliéndose la condición de que los valores propios, los intereses de las autoridades y de la comunidad estén seguros, y que haya una amplia posibilidad de ajuste, las politicas de la no-alineación buscarán la integración de la comunidad doméstica con los otros sistemas mundiales.

El papel del estado consiste esencialmente en proteger los intereses de los sistemas y de las partes de los sistemas que están dentro de él, y por eso mismo, en la politica exterior su papel consiste en actuar no como una barrera a las transacciones, sino como un filtro de ellas, para asegurar qugiel cambio cae dentro de la capacidad de absorción que tiene el sistema sin què se destruyan sus valores sociales. Agregado a lo anterior, el papel del estado consiste en actuar positivamente en la búsqueda de flexibilidad y de ajuste, y en la promoción de valores. Un análisis de sistemas no deberá concluir que los estados devienen cada vez menos importantes en el contexto de la sociedad mundial. Al contrario, aunque su papel pueda estar en proceso de cambio, la importancia del estado se hace cada vez más grande, a medida de que aumentan las iniciativas dentro de sus limites en orden a promover el bienestar, por medio de la redistribución de los recursos, y como un contrapeso a los intereses de los sistemas más amplios, frente a los valores internos que de esta manera se van creando.

También varia el grado en que las autoridades buscan aislarse para proteger su área respecto de las influencias externas. La razón de esto está tambien en la demanda interna. En situaciones en las que el papel de las autoridades consiste en actuar de cojinete entre las influencias internas $y$ externas, de modo de facilitar respuestas dentro de sus limites a intercambios con sistemas más amplios, y eliminar asi la significación de los límites, resulta más activa su operación en los asuntos internos que en los externos. Para que esas situaciones se den, tiene que existir un alto grado de unidad interna y de satisfacción con la operación de los sistemas más amplios. Cuando hay insatisfacción interna, las autoridades se esfuerzan por aislar lo económico, lo social, lo ideológico y los otros sistemas, dentro de sus propios limites, separándolos de la influencia de otros más amplios. En casos como éstos, el bienestar es un valor de menor importancia que la seguridad. Un estado que busca proteger una empresa o una ideologia dentro de sus limites, respecto de los cambios o del comercio que se lleva a cabo en sistemas 
comerciales o ideológicos más amplios, estará en conflicto con otros estados respecto a esos sistemas. Aumentará asi la inseguridad, y el bienestar pasará a. ser un valor secundario. El Welfare State resulta asi dependiendo de su contorno: puede progresar solamente cuando en los otros estados hay condiciones de estabilidad, y no tiene que defenderse contra la demanda de severas transacciones o de intervención de hecho en sus asuntos.

De este modo, tanto el análisis teorético como la experiencia diplomática han creado dos sistemas de pensamiento, dos perspectivas de la sociedad mundial. Las politicas de poder resultan aplicables a uno, las politicas de independencia de los estados más pequeños aplicables al otro. La educación, las comunicaciones, el desarrollo industrial, la disuasión nuclear, las demandas de bienestar y toda una hueste de influencias sociales, politicas, económicas y estratégicas, nos guian inexorablemente a una sociedad mundial de sistemas tipo, que van forzando a los estados a proseguir politicas aplicables a él. Pueden darse los siguientes ejemplos de algunas de las hipótesis que emergen de un sistema de pensamiento conductista, y que pueden resultar del todo inaceptables para cualquiera que esté acostumbrado a otro sistema. La soberania y el nacionalismo son rasgos favorables a la sociedad internacional, y el poder internacionalizado es a la vez impracticable e indeseable (aunque las organizaciones internacionales, como las organizaciones voluntarias funcionales, son medios útiles para la cooperación entre los estados). La seguridad colectiva, las alianzas, y cualquier otra estructura que contrarie el cambio y preserve el orden existente, son fuentes potenciales de conflicto. Los sistemas internacionales, la existencia de soberania, la agresividad o las motivaciones de poder de los estados, los conflictos ideológicos y otros conflictos sobre los valores, no son una fuente importante de conflicto. La fuente de los conflictos está en la politica interna, en el fracaso por parte de los estados en ajustar o en alterar las situaciones, y en la lucha de los estados por defender sus internos sistemas de valores.

La teoria del poder ha sido una explicación útil de la sociedad internacional durante la etapa de exploración y de desarrollo. Es ahora un trabajo inútil el tratar de mantenerla y hacerla calzar con situaciones que han variado. También hay toda una consistente teoria conductista que da cuenta mejor de ciertos aspectos de la sociedad mundial que emerge. Es inútil tratar de repetirla para hacerla calzar con las situaciones del pasado. Es importante determinar conscientemente las afirmaciones y la trama conceptual con que uno opera. En un sistema de poder, los componentes lógicos son las alianzas, las balanzas de poder, el papel especial de los estados más poderosos, el régimen de la ley y las instituciones internacionales que organizan el poder. En el sistema conductista, que trata de explicar la conducta del estado en situaciones en que el empleo del poder provoca su propia oposición, el interés analitico está en la capacidad del estado para alterar las metas politicas, para 


\section{J. W. Burton / No-alineación y politica mundial contemporánea}

adoptar medidas alternativas y para hacer ajustes internos frente a los sucesos del exterior; y, consecuentemente, el estudio de las relaciones entre los estados trata primariamente de los procesos de gestación de decisiones. Ambos sistemas son lógicos y son aplicables a algunos de los aspectos de la sociedad internacional; pero, al hacerse cualquier juicio, observación o hipótesis sobre alguna situación particular, es necesario hacer una consciente referencia a un sistema o al otro. Es aun más importante al compararse los sucesos ocurridos en periodos históricos diferentes dejar en claro estas tramas de aplicación. En cuanto a la pregunta de cuál sea el valor de los estudios conductistas de las relaciones internacionales, la respuesta que sugiere uno u otro sistema es muy débil. En cuanto a la pregunta de cuál sea el valor que el neutralismo tiene en un estado nuevo, la respuesta es también muy débil, o muy fuerte, según sea el sistema de pensamiento. La respuesta a la pregunta acerca de si deben romperse las relaciones entre los estados como una medida de coerción, es sí o ès no, según sea la conceptualización base que se emplea. $¿$ Es el conflicto politico interno una fuente importante de conflictos internacionales? La personalidad de los lideres, ¿ $¿$ es un factor de importancia? ¿ $E s$ la soberania del estado una fuente de conflicto? $¿$ Son deseables las instituciones internacionales que refuerzan el poder? Estas y muchas otras preguntas en esta área recibirán un tipo de respuestas en base a uno de los sistemas de pensamiento y otro tipo en base al otro.

Dada la naturaleza de la sociedad mundial y de los valores que persigue, la no-alineación nos parece un concepto adecuado como punto de partida en el análisis. Aun cuando no hubiese estados que reclamaran la no-alineación, ésta de todos modos representaria la norma o la situación contra la cual puede calcularse una realidad. Asi como la competencia perfecta es el modelo contra el cual se calcula la situación monopolistica, o la conducta normal del individuo es el modelo contra el cual se calcula la conducta anormal. Tenia razón Sukarno, cuando en Belgrado comentaba que "cualquier nación, sin excepción, desea básicamente una politica de este género, sabe que ella podria cooperar a la preservación de la paz mundial adoptando una politica similar. Pero la posibilidad de llevar a cabo una politica de no-alineación depende no sólo de los deseos. Puede darse que por el trasłfondo histórico, por los intereses nacionales inmediatos, por la posición geográfica, muchos paises no tengan la oportunidad, o ni siquiera la capacidad, para llevar a cabo una politica de no-alineación". (Ver mi propia exposición de la no-alineación como norma, en International Relations, Cambridge, 1965). El peso de la responsabilidad cae sobre los estados que emprenden alianzas para justificar sus escalas de valores y sus politicas en casos particulares, y no sobre los que dictan la norma de conducta sobre la no-alineación. El gobierno que carece de apoyo popular para sus propios asuntos, que enfrenta cambios sociales y politicos, y que por esa razón busca refuerzo en una potencia extranjera, justifica alianzas al buscar seguridad, en aras de su propia supervivencia. 
Pero no deberia justificar su propia conducta criticando las politicas de independencia en otros gobiernos que están legitimizados en sus procesos sociales y politicos, y que no requieren de alianzas extranjeras con otros gobiernos que compartan sus filosofias.

\section{NATURALEZA DEL GONFLICTO INTERNACIONAL}

Los conflictos entre los estados surgen inevitablemente en este sistema internacional, dominado por el esfuerzo por asegurar - a nivel local, nacional e internacional - los derechos a participar en las decisiones y en las reformas politicas. Evan Luard ha mostrado que este periodo, desde la Primera Guerra Mundial, ha sido uno de los que un mayor número de conflictos internacionales hayan tenido su origen en guerras civiles (Conflict and Peace in the Modern International System, Little, Brown and Co., 1968). Modelski y Rosenau han analizado el modo en que los disturbios internos conducen a conflictos internacionales (Rosenau, J. N., editores, International Aspects of Civil Strife, Princeton, 1964). Los movimientos de independencia comenzaron siendo luchas civiles, y en Asia y Africa especialmente, fueron seguidos de conflictos sociales y políticos posteriores, a medida que se fueron haciendo demandas sociales y politicas en el proceso de decisiones.

Está claro que estos movimientos son necesarios en las sociedades en desarrollo, y está igualmente claro que se llevan a cabo suavemente, con un minimo de violencia cuando las autoridades legales no se colocan en posición de obtener ayuda externa o de usar la fuerza para compensar su propia falta de legitimidad. Sin embargo, el derecho internacional tradicional parece haber dado a las grandes potencias el derecho a intervenir en las revueltas civiles. Han dado evidencia de esto las invasiones occidentales en Asia, Africa, Medio Oriente y América Latina, desde 1945. La Unión Soviética ha adoptado en sus relaciones internacionales el mismo comportamiento de gran potencia. A menudo los estados que no logran mantenerse a si mismos, están ansiosos de sacar ventaja de esto, al igual que las grandes potencias. Las instituciones tradicionales en el sistema internacional actúan pesadamente en favor del statu quo. Como nunca se hacen necesarias reformas sociales y politicas en muchos de los nuevos estados que han emergido desde la Segunda Guerra Mundial. En su mayor parte se trata de estados no-álineados. Pero, los gobiernos, en muchos de estos estados, se han refugiado en la misma estructura de poder de la sociedad mundial que la no-alineación está desafiando.

Hay múltiples ejemplos de la manera cómo los gobiernos han hecho esto. Las tropas británicas fueron llamadas por gobiernos de Africa Oriental para 


\section{J. W. Burton / No-alineación y politica mundial contemporánea}

que ayudaran a superar las revueltas internas. Puede darse tal vez argumentos-a favor de esta búsqueda de asistencia por parte de los estados recientemente organizados. Pero, ¿es tan claro que dichos gobiernos tienen un status legitimizado y que están cumpliendo con las expectativas del pueblo? ¿Está claro que la revuelta no ha sido provocada por las condiciones en que cstaba el ejército o los participantes en la misma revuelta? ¿Es mediante la coerción que se obtiene la lealtad a un gobierno, o es algo que debe ser ganado? Los gobiernos de Singapur y de Malasia parecen mirar con nostalgia el retiro de los británicos de sus bases en esos lugares. ¿Se debe esto al miedo de conflictos raciales o comunitarios, y es tan claro que dichos conflictos no son una respuesta a politicas discriminatorias que favorecen a los malayos en Malasia, y a politicas que suprimen la oposición en Singapur? En Africa no se tolera la oposición si ésta significa una amenaza electoral al gobierno. Se argumenta en Kenia que la oposición debe limitarse a hacer sugerencias constructivas. El año pasado no se permitió a los candidatos de oposición presentarse a las elecciones, bajo el pretexto de una infracción maquinada por el gobierno. Se mirará con buenos ojos a los experimentos de partidos únicos. Pero la total exclusión de los puntos de vista de la oposición, y la eliminación por detención o por otros medios de las personas potenciales competidoras en el liderazgo politico reciben también simpatia, con su consiguiente desasosiego interno y su refuerzo desde el extranjero. En Africa se percibe una marcada discriminación racial contra los asiáticos; pero al mismo tiempo se nota una creciente actitud de coalición contra la discriminación que sucede en Rodesia y Sudáfrica. Los problemas raciales son muy semejantes a los problemas de clases: en Africa, los asiáticos $y$ los blancos son los ricos, los africanos son los pobres. El conflicto real se plantea entre los ricos y una clase, y las soluciones a esto no son los remedios que los africanos estarian dispuestos a emplear con los blancos y los asiáticos. Un análisis falso, aunque politicamente conveniente, está sacando a los gobiernos africanos del marco de la no-alineación, hacia la constitución de alianzas para combatir una situación que se ha hecho presente a causa de su misma actuación en esos lugares. Los gobiernos miembros de la Organización de la Unidad Afriçana han acordado entre ellos que no deberia haber cambios limitrofes en Africa. Esto resulta increible si se toma en cuenta la forma cómo los gobiernos coloniales trazaron dichos limites, y se consideran las criticas que los mismos africanos plantcaron respecto a esos limites. Un paso constructivo habria sido el de revisar cuidadosamente la situación de los limites y eliminar asi algunas de las más serias causales de conflictos. Pero: esos gobiernos han actuado más como grupos de poder que trataban de manten erse a si mismos mediante" alianzas que como grupos preocupados de los intereses presentes y futuros de Africa. En la India, la noalineación se ha visto amenazada por politicas de reacción, por influencias internas de carácter conservador. El combate que en India debió dirigirse en 
pro de metas sociales y politicas se ha desviado hacia el anticomunismo, particularmente contra China, amenazando así el status no-alineado de la India. Nigeria hizo uso de los argumentos tradicionales en pro de la soberania para justificar la supresión de los rebeldes, y como fundamento para conseguir equipo militar de Gran Bretaña y de la Unión Soviética. Podriamos ir de ejemplo en ejemplo: los gobiernos de los estados nuevos no han llevado a cabo ese mismo idealismo que proclamaron ser su motivación fundamental, y que vendria a distinguir la conducta interna - y por lo mismo la externa - de un estado no-alineado, de la conducta tradicionalmente empleada por los gobiernos de los estados más poderosos. La no-alineación requiere una conducta acorde a un modelo. En la práctica, los estados nuevos están actuando más bien de acuerdo con el modelo que rechazaron cuando se proclamaron no-alineados. La útil distinción planteada por los gobiernos de los estados nuevos entre autodeterminación y sucesión, deviene cada vez menos clara a medida de que los grupos tribales, étnicos, y otros, hacen demandas de efectiva participación en las decisiones que los afectan. Esta demanda de participación es universal e irresistible, sea a nivel del estado, del gobierno local o de la universidad. Los gobiernos de los estados recientemente independizados no pueden restringir esas influencias hacia la independencia que de hecho originalmente los crearon, y que ahora les exigen cambios. En su debido momento, el dictador indigena no es más bienvenido que el poder colonial extranjero, y se produce el quiebre del sistema basado en privilegios. Sin embargo, esto no se lleva a efecto sin resistencias. Un medio de resistir es la ayuda extranjera, y otro, el entendimiento tácito de que la represión de las minorias es asunto de jurisdicción interna y no una infracción a los derechos humanos.

Hay una tenue distinción entre alianzas y acuerdos regionales que comprenden a estados no-alineados, que provoca no menos abuso que la distinción entre autodeterminación y sucesión. Tomemos por ejemplo la Liga Arabe. Tiene muchos rasgos de alianza. Surge la cuestion, $\dot{c}$ hay circunstancias en las que los estados no-alineados puedan asociarse para preservar su seguridad sin infringir el principio de la no-alineación? A primera vista, la relación de defensa entre los árabes parece más que justificada - pero, a primera vista, también podria uno justificar la OTAN o el Pacto de Varsovia. La pregunta que necesita una respuesta es si estas alianzas no son autodestructivas. ¿No crean de hecho las mismas condiciones de amenaza que pretendieron suprimir? No es tan claro que el mismo temor árabe respecto a Israel no haya tenido por resultado un Israel militarizado y ofensivo. ¿No están propensos los estados no-alineados a caer en la misma trampa que las grandes potencias, al adoptar sus mismos conceptos tradicionales sobre la sociedad mundial? $i$ No significa esto negar los supuestos básicos de la no-alineación, que formulaban el que los estados nuevos no eran parte principal en las dos guerras mundiales, que no estaban directa- 


\section{J. W. Burton / No-alineación y politica mundial contemporánea}

mente comprometidos en la Guerra Fria entre Este-Oeste, y que no tenían motivos para temerse unos a otros, ya que no habia planes de unos contra los otros?

Nada de esto es sorprendente. El asunto es que las influencias que están operando a todo lo largo del mundo, por ejemplo, las demandas de participación en las decisiones, y de un creciente bienestar y de oportunidades para el desarrollo, que son las influencias que hacen importante la no-alineación en la sociedad mundial, aun no han conseguido que se produzcan en los estados nuevos los cambios revolucionarios en los procesos de gobierno, necesarios para dar importancia a la no-alineación. Es esta resistencia interna al cambio la que está amenazando a la no-alineación, mucho más que las amenazas externas. De hecho, muy a menudo las amenazas externas aparecen en función de la resistencia interna a los cambios sociales y politicos. En un mundo de ideologias en conflicto, siempre habrá un estado que, en un conflicto interno, descubra algún interés en un lado o en el otro, y se produzca entonces un desborde que cree las condiciones de un conflicto internacional.

En resumen, la no-alineación es una politica que puede ser llevada a cabo efectivamente sólo por los gobiernos que son sensibles a las demandas internas, y que están satisfaciendo las necesidades y las aspiraciones del pueblo a quien gobiernan. Desde esta posición de fuerza y sólo desde ella, pueden los gobiernos llevar a cabo politicas de independencia e intervenir activamente en los asuntos mundiales, en base a sus propias e independientes consideraciones sobre los méritos de cada caso.

\section{LA NO ALINEACIÓN Y LOS ESTADOS DESARROLLADOS}

Los países que llenan los requerimientos de la no-alineación se encuentran entre aquellos estados más antiguos que tienen gobiernos, sean éstos parlamentarios de partidos o de algún otro tipo, que son sensibles a los valores e intereses del pueblo a quien gobiernan. Hemos hecho referencia a Francia, y a la manera cómo De Gaulle ha desáfiado integramente la concepción tradicional de la sociedad mundial. Desde que se liberó de sus responsabilidades coloniales, Francia ha tomado una linea independiente en muchos puntos. También Gran Bretaña cumple con los requerimientos internos para ser un estado no-alineado, y una vez que se libere de los compromisos financieros que la tienen atada a Estados Unidos, desempeñará un papel cada vez más independiente y más activo en los asuntos mundiales. Yugoslavia se ha mostrado a si misma como uno de los estados más adictos a la no-alineación, y su gobierno es también a la vez uno de los más responsables frente a los cambios en las necesidades y en los valores internos. Para que la no-alineación llegue a ser una norma, se requiere un alto grado de normalidad interior. 
En esta perspectiva quisiera reafirmar la naturaleza y la importancia de la no-alineación, desde el punto de vista de las ventajas para 1969, mirando atrás dos décadas, hacia los origenes de la no-alineación, y adelante, hacia su posible desarrollo. Las alianzas juntan a grandes y pequeños estados, cuyos gobiernos, en muchos casos, no lograrian sobrevivir sin el apoyo de las grandes potencias. Los más inseguros internamente serán los socios más leales. Las mismas potencias hegemónicas están reaccionando defensivamente frente a las alteraciones de las condiciones mundiales y a los desafios de las instituciones que ellas valoran. Estados Unidos busca defender a los gobiernos que estén dispuestos a apoyar las instituciones sociales $y^{\prime}$ politicas que él mismo tiene. Las politicas del socialismo planteadas en los estados de Asia y en Gran Bretaña, en el periodo inmediatamente posterior a la guerra, parecieron entenderse inicialmente como un desafio a los conceptos institucionales sociales y politicos que universalmente Estados Unidos estaba sustentando. La no-alineación empezó siendo calificada de inmoral, porque implicaba una falta de total apoyo al modo americano de vivir, y por lo menos una tolerancia a los valores e instituciones comunistas. Fueron reacciones defensivas. El hecho de que el socialismo, la no-alineación y el comunismo aparecieran como importantes amenazas contra la sociedad norteamericana, sugiere una falta de confianza en la estabilidad de las propias instituciones o en su importancia social.

Hay temas en los que solamente podemos especular, ya que no tenemos investigaciones sociológicas adecuadas. Sin embargo, es importante observar que Estados Unidos tiene esas instituciones de privilegio social, marcadas desigualdades en los ingresos, tensiones raciales e inquietud politica, $y$ alianzas entre el ejército y los negocios, que han sido asociadas con el tipo de régimen que se ha esforzado en apoyar en Asia y en América Latina. En términos de su propio sistema de valores - la democracia, la moralidad, la libre empresa y la observancia de la ley-, Estados Unidos está en la práctica muy lejos de la imagen que proyecta hacia si mismo. En algunos niveles académicos hay preocupación por esto.

Un análisis similar podria aplicarse a la Unión Soviética. Aparentemente, su gobierno siente que los cambios en los valores y en las instituciones dentro de su esfera de influencia plantean una amenaza, no sólo a su seguridad fisica, sino también a los valores e instituciones dentro de la Uniôn Soviética.

Si esta perspectiva es válida, las grandes potencias son centros de alianzas, alrededor de los cuales se congregan otros estados más pequeños, no porque unos sean grandes potencias y los otros tengan problemas de seguridad, sino porque ambos tienen condiciones internas inestables, que pueden ser sustentadas sólo mediante el apoyo del poder. Un Estados Unidos o una Unión Soviética que hubieran consolidado sus instituciones y conseguido un status del todo legitimizado, no necesitarian estructuras de alianza para su 


\section{J. W. Burlon / No-alineación y politica mundial contemporánea}

seguridad. Es instructivo examinar cuáles son los miembros de las alianzas, sopesar su confiabilidad en cuanto tales, y luego calcular el nivel de autoridad legitimizada que en cada caso tiene el gobierno legal. No me atreveria a plantear que es posible establecer definiciones operacionales ni medidas para la confiabilidad de la condición de miembros en una alianza y para la legitimidad de la autoridad. Me parece, si, que cada uno de nosotros está en condiciones de hacer juicios que tengan alguna validez:

$\begin{array}{lll}\begin{array}{l}\text { Miembros de } \\ \text { la orax }\end{array} & \begin{array}{l}\text { Miembrosde } \\ \text { la SEATo }\end{array} & \begin{array}{l}\text { Miembros del } \\ \text { Paclo de Varsovia }\end{array} \\ \text { Bélgica } & \text { Australia } & \text { Albania } \\ \text { Canadá } & \text { Gran Bretaña } & \text { Alemania Oriental } \\ \text { Dinamarca } & \text { Estados Unidos } & \text { Bulgaria } \\ \text { Estados Unidos } & \text { Filipinas } & \text { Checoslovaquia } \\ \text { Francia } & \text { Francia } & \text { Hungria } \\ \text { Gran Bretaña } & \text { Nueva Zelandia } & \text { Polonia } \\ \text { Grecia } & \text { Pakistán } & \text { Rumania } \\ \text { Holanda } & \text { Tailandia } & \text { Unión Soviética } \\ \text { Islandia } & & \\ \text { Italia } & & \\ \text { Luxemburgo } & & \\ \text { Noruega } & & \\ \text { Portugal } & & \\ \text { República Federal } & & \\ \text { de Alemania } & & \\ \text { Turquia } & \end{array}$

Considero que ha llegado el momento de realizar una radical revisión del concepto de no-alineación, de sus afirmaciones básicas y de sus orientaciones politicas. Ha mostrado no carecer de importancia para la sociedad mundial y para los valores que persiguen los estados nuevos, excepto en los casos en que los mismos gobiernos nuevos han contribuido a restarle importancia al buscar apoyo en el extranjero, al emprender politicas de poder y al anteponer su seguridad politica interna al progreso politico y social que va asociado con los derechos politicos, de los que la independencia nacional es sólo el punto de partida. El futuro se encargará de mostrar la importancia de la noalineación para todo estado que esté satisfaciendo las necesidades de su pueblo, en especial la necesidad de tomar parte activa en el proceso de decisiones. 